\title{
CORRECTION
}

\section{Correction to: Management of Patients with Type 2 Diabetes with Once-Weekly Semaglutide Versus Dulaglutide, Exenatide ER, Liraglutide and Lixisenatide: A Cost-Effectiveness Analysis in the Danish Setting}

Peter Gæde · Pierre Johansen • Christian Klyver Tikkanen •

Richard Fulton Pollock - Barnaby Hunt - Samuel Joseph Paul Malkin

Published online: May 31, 2019

(c) The Author(s) 2019

Correction to: Diabetes Ther

https://doi.org/10.1007/s13300-

019-0630-6

In the original publication, Figs. 3 and 5 and the final sentence in the final paragraph of Results/ Sensitivity Analyses were incorrectly published. The corrected statement and the figures are given below.
Additionally, the last few lines under the heading 'Sensitivity Analyses' should read as:

At a willingness-to-pay threshold of DKK 250,000 per QALY gained (a representative value based on GBP 20,000 in the UK), the probabilities of once-weekly semaglutide $0.5 \mathrm{mg}$ and $1 \mathrm{mg}$ being considered cost-effective were $72.4 \%$ and $96.5 \%$, respectively, versus dulaglutide $1.5 \mathrm{mg}$ (Fig. 5).

The original article can be found online at https://doi. org/10.1007/s13300-019-0630-6.

P. Gæde

Department of Endocrinology and Cardiology,

Slagelse Hospital, Slagelse, Denmark

P. Johansen

Novo Nordisk A/S, Søborg, Denmark

C. K. Tikkanen

Novo Nordisk Scandinavia AB, Copenhagen,

Denmark

R. F. Pollock

Covalence Research Ltd, London, UK

B. Hunt · S. J. P. Malkin ( $\square)$

Ossian Health Economics and Communications, Basel, Switzerland

e-mail: malkin@ossianconsulting.com 


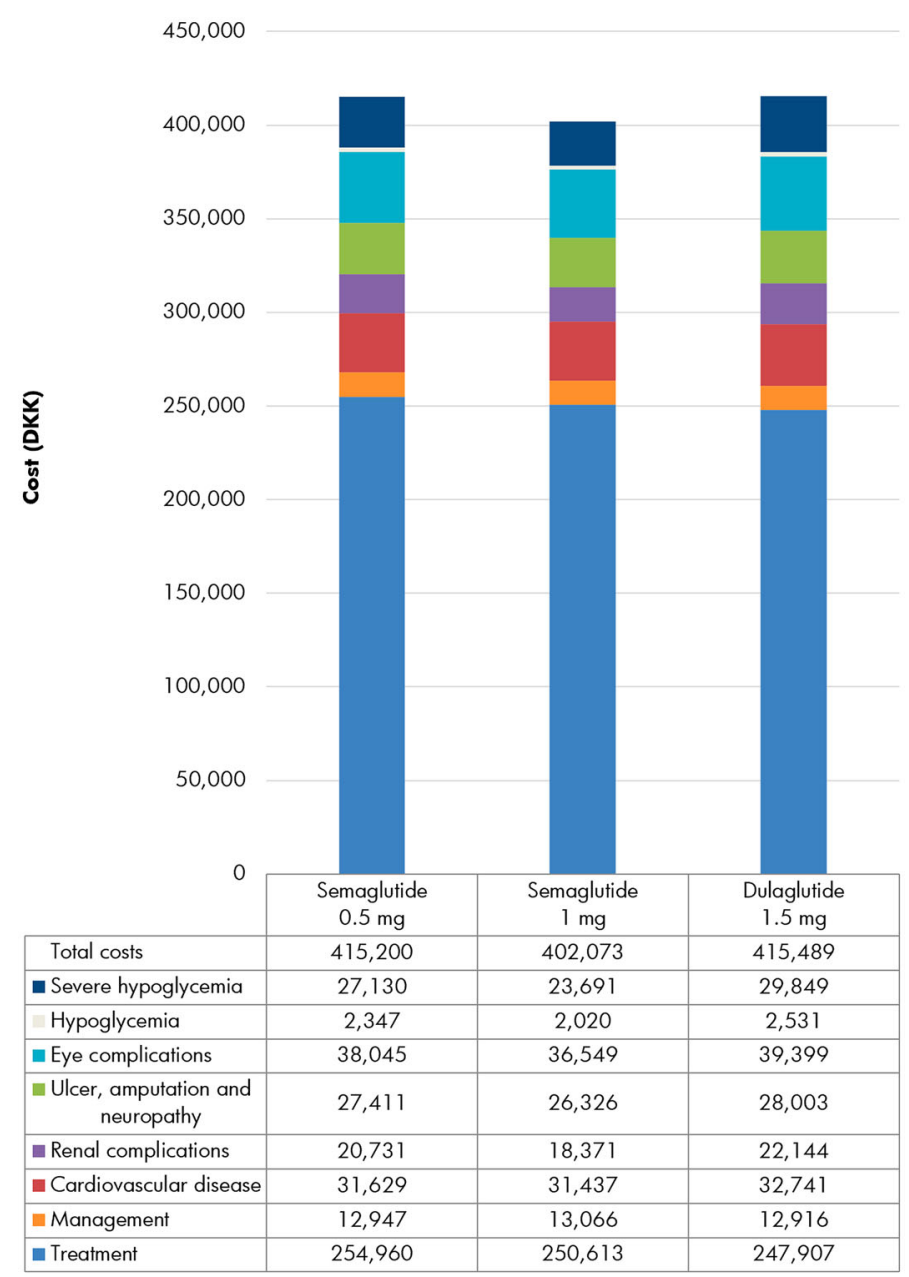

Fig. 3 Discounted direct costs over patient lifetimes in the primary analysis based on SUSTAIN 7. DKK 2017 Danish kroner 


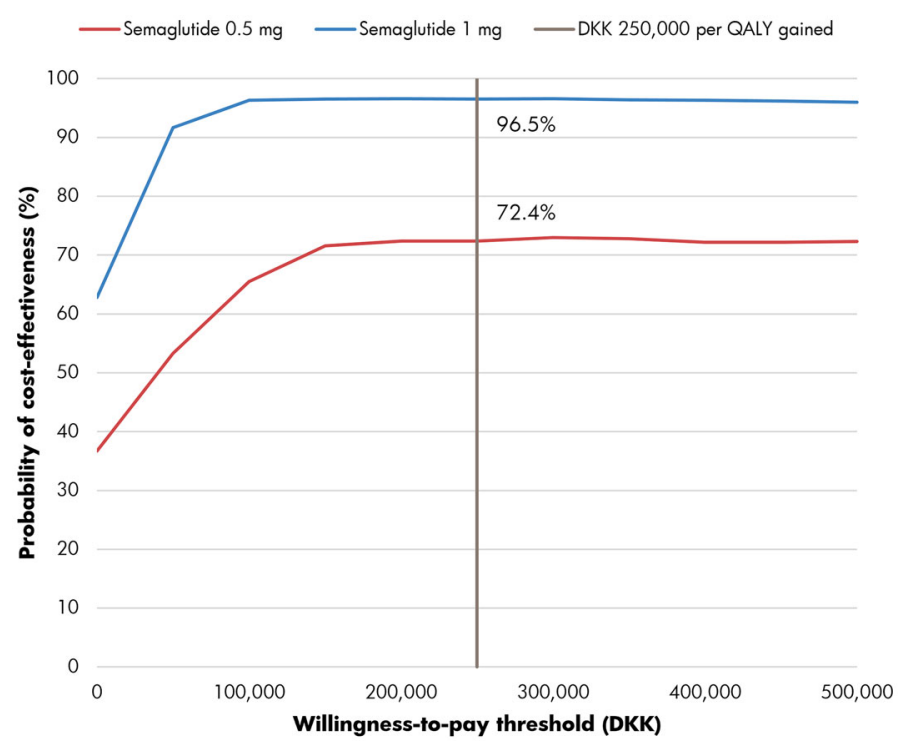

Fig. 5 Cost-effectiveness acceptability curve for the primary analysis versus dulaglutide, based on SUSTAIN 7. DKK 2017 Danish kroner, $Q A L Y$ quality-adjusted life year

Open Access. This article is distributed under the terms of the Creative Commons AttributionNonCommercial 4.0 International License (http:// creativecommons.org/licenses/by-nc/4.0/), which permits any noncommercial use, distribution, and reproduction in any medium, provided you give appropriate credit to the original author(s) and the source, provide a link to the Creative Commons license, and indicate if changes were made. 